\title{
Comparison of Bacterial Community of Healthy and Erwinia amylovora Infected Apples
}

\author{
Su-Hyeon Kim ${ }^{1}$, Gyoengjun Cho ${ }^{1}$, Su In Lee ${ }^{2}$, Da-Ran Kim ${ }^{1}$, and Youn-Sig Kwak $\mathbb{1}^{1,2 *}$ \\ ${ }^{1}$ Division of Applied Life Science (BK21Plus) and Research Institute of Life Science, Gyeongsang National University, \\ Jinju 52828, Korea \\ ${ }^{2}$ Department of Plant Medicine, Institute of Agriculture \& Life Science, Gyeongsang National University, Jinju 52828, \\ Korea
}

(Received on April 22, 2021; Accepted on May 17, 2021)

Fire blight disease, caused by Erwinia amylovora, could damage rosaceous plants such as apples, pears, and raspberries. In this study, we designed to understand how $E$. amylovora affected other bacterial communities on apple rhizosphere; twig and fruit endosphere; and leaf, and fruit episphere. Limited studies on the understanding of the microbial community of apples and changes the community structure by occurrence of the fire blight disease were conducted. As result of these experiments, the infected trees had low species richness and operational taxonomic unit diversity when compared to healthy trees. Rhizospheric bacterial communities were stable regardless of infection. But the communities in endosphere and episphere were significanlty affected by $E$. amylovora infection. We also found that several metabolic pathways differ significantly between infected and healthy trees. In particular, we observed differences in sugar metabolites. The finding provides that sucrose metabolites are important for colonization of $E$. amylovora in host tissue. Our results provide fundamental information on the microbial community

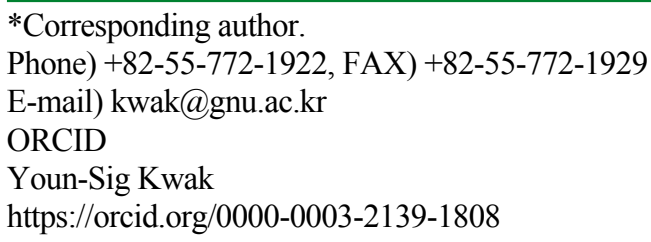

(c) This is an Open Access article distributed under the terms of the Creative Commons Attribution Non-Commercial License (http:// creativecommons.org/licenses/by-nc/4.0) which permits unrestricted noncommercial use, distribution, and reproduction in any medium, provided the original work is properly cited.

Articles can be freely viewed online at www.ppjonline.org. structures between $E$. amylovora infected and uninfected trees, which will contribute to developing novel control strategies for the fire blight disease.

Keywords : endosphere, episphere, Erwinia amylovora, microbiome, rhizosphere

Apple (Malus domestica) is widely cultivated and one of the most economically important agricultural products (Wassermann et al., 2019; Zheng et al., 2020). Apples have various nutrition-rich molecules, such as polyphenols and vitamins that benefit human health (Wassermann et al., 2019). In 2020, apple production in China (40.5 million ton, Mt), followed by the United States (4.6 Mt), Turkey (4.3 Mt), India (2.3 Mt), Russia (1.5 Mt), and South Korea $(0.5 \mathrm{Mt})$ and around the world were around $83 \mathrm{Mt}$ of apples are produced annually (Ritchie and Roser, 2020).

Various diseases occur during apple cultivation, most commonly, scabbing (Venturia inaequalis), powdery mildew (Podosphaera leucotricha), and fire blight (Erwinia amylovora) (Vincent et al., 2010). The fire blight pathogen causes significant damage in rosaceous plants such as apples, pears, and raspberries. Apples especially face considerable economic losses when affected (Born et al., 2017; Bubán and Orosz-Kovács, 2003). Since the fire blight disease was reported in the United States in the 1780s, it has spread to more than 50 countries including Europe, Kyrgyzstan, and South Korea (Zhao et al., 2019). The fire blight disease exhibits symptoms of burning from reddish to black in leaves, twigs, flowers, and fruits. E. amylovora infected branches, twigs, and fruits develop a watery ooze during high humidity (Ait Bahadou et al., 2018). During the flowering stage, E. amylovora can be spread to flowers 
by insects, wind, or rain (Cui et al., 2021; van der Zwet et al., 2012). However, the disease continuously reoccurs, and causes significant damage in apple production (Aćimović et al., 2015).

To manage the fire blight disease, copper-based bactericides are widely used, but these copper compounds have a high risk of phytotoxicity (Aćimović et al., 2015; Sholberg et al., 2001). Control of the disease by antibiotics, such as streptomycin and oxytetracycline, has limited effect. Additionally, the antibiotics facilitate the emergence of resistant pathogens (Aćimović et al., 2015; McManus et al., 2002). Alternatively, biological control for the fire blight disease using beneficial microorganisms has been considered as the most eco-friendly and sustainable control method. Bacillus subtilis BD170, Lactobacillus plantarum PM411, TC54 and TC92, Pseudomonas fluorescens EPS62e, and Pantoea agglomerans E325 are reported as biological control agents to manage fire blight disease (Broggini et al., 2005; Cabrefiga et al., 2007; Pusey et al., 2011; Roselló et al., 2013).

Plant microbiota have an important role in plant growth and significant impact on abiotic and biotic stress reduction of the plant (Kim et al., 2019a; Wassermann et al., 2019). Understanding microbial ecological information such as pathogen mobilization, dissemination, and interaction with other microbes in the environment are critical factors in promoting plant wellness (Bengtsson-Palme et al., 2018). However, plant associated microbial ecosystems have not been studied in the past due to a lack of technology, which currently is progressing with the appearance of metagenomic technology. Accordingly, the metagenomics approach is considered a revolutionary field of microbial ecology through techniques without culturing method (Williamson and Yooseph, 2012). Despite the knowledge of pathogen-infected plant microbiome community structures, only limited information is available on apples and their microbiota. In this study, we compared the structure of bacterial community, species abundance, diversity, and metabolite patterns between the fire blight diseased and healthy apples.

Bacterial community structures were compared in healthy and unhealthy (fire blight diseased) apple trees (cv. Fuji). The unhealthy samples were obtained from two different orchards A and B (Chungju province, South Korea; GPS information is not disclosed in accordance with regulations), and orchard $\mathrm{C}$, the fire blight disease free orchard located in Eumsung province, South Korea. Five trees were randomly selected in each orchard for sampling. In E. amylovora infected trees, typical fire blight symptoms appeared on twigs and fruits (Supplementary Fig. 1). Symptoms and signs of fire blight were observed overall from $70 \%$ to $80 \%$ trees. The infected twigs and leaves turned from brown to black from the tip. Immature fruits of apple showed signs of bacterial ooze colored yellow and orange (Supplementary Fig. 1).

From each tree, rhizosphere soil, episphere fruit and leaf, endosphere fruit and twig samples were collected in June 2020. The rhizosphere soil was collected from root surface $1-3 \mathrm{~mm}$ and filled in a 50-ml tube $(n=5)$. Episphere samples were prepared that fruits (each tree, $n=3-5$ ) and leaves (each tree, $n=10-15$ ). Endosphere sample twigs (each tree, $n=2-3$ ) were collected that cut inside 10-length from the tip and leaves (each tree, $n=10-15$ ). For isolation of episphere microbiomes, the fruit was peeled leaving only the pulp using a disinfected knife, $10 \mathrm{~g}$ of sample were transferred into a 50-ml tube. Twig ( $1.5 \mathrm{~g})$ and leave $(5 \mathrm{~g})$ were weighed and transferred to a 50-ml tube. Before DNA extraction, samples in a 50-ml tube were sonicated at $35 \mathrm{kHz}$ with $50 \mathrm{ml}$ of $1 \times$ phosphate buffered saline (PBS) buffer (10 PBS: $80 \mathrm{~g}$ of NaCl, $2 \mathrm{~g}$ of KCl, $1.44 \mathrm{~g}$ of $\mathrm{Na}_{2} \mathrm{HPO}_{4}, 2.4$ $\mathrm{g}$ of $\mathrm{KH}_{2} \mathrm{PO}_{4}$, per liter adjusted to a $\mathrm{pH}$ of 7.4) for $45 \mathrm{~s}$ and vortexed for $30 \mathrm{~s}$ three times (Kim et al., 2019a, 2019b; Yao et al., 2019). The suspension was transferred to a new tube, then centrifuged at $1,968 \times \mathrm{g}, 4^{\circ} \mathrm{C}$ for $20 \mathrm{~min}$ and the supernatant was discarded. The tube was filled with $5 \mathrm{ml}$ of $1 \times$ PBS buffer and $50 \%$ glycerol in the same proportion and stored at $-80^{\circ} \mathrm{C}$. To isolate microbiomes in the endosphere. The sonicated samples were sterilized in $70 \%$ ethanol for $30 \mathrm{~s}, 1 \% \mathrm{NaOCl}$ for $30 \mathrm{~s}$, then washed in $\mathrm{ddH}_{2} \mathrm{O}$ for 2 times and dried for $1 \mathrm{~h}$ at a clean bench at room temperature. Completely dry samples were grinded with liquid nitrogen and stored at $-80^{\circ} \mathrm{C}$. Total DNA was extracted with a FastDNA SPIN Kit for Soil (MP Biomedicals, Irvine, CA, USA) using $0.5 \mathrm{~g}$ of rhizosphere, $0.3 \mathrm{~g}$ of endosphere, and $0.5 \mathrm{ml}$ of episphere. DNA was extracted following the manufacturer's instruction. The quality and quantity of DNA were verified using NanoDrop 2000 (Thermo Fisher Scientific, Waltham, MA, USA)

DNA was diluted to $5-8 \mathrm{ng} / \mu 1$ and amplified by $341 \mathrm{~F}-$ 805R primer including overhang adapter sequences and PNA probes (pPNA, mPNA) (Lundberg et al., 2013) to block plant-derived mitochondrial chloroplasts (Supplementary Table 1). PCR reaction of rhizosphere samples was conducted with a total $40 \mu 1$ of mixture ( $2.5 \mu 1$ of DNA, 1 $\mu 1$ of each primer [10 pmol], $20 \mu$ of $2 \times$ PCR buffer for KOD FX Neo, $4 \mu \mathrm{l}$ of dNTPs [2 mM], $0.3 \mu \mathrm{l}$ of KOD FX Neo [1.0 U/ $\mu$ l; Toyobo, Tokyo, Japan] with $\mathrm{ddH}_{2} \mathrm{O}$ added to $40 \mu \mathrm{l}$ ). PCR reaction of rhizosphere samples followed the conditions: $95^{\circ} \mathrm{C}$ for $3 \mathrm{~min}, 25$ cycles condition were $95^{\circ} \mathrm{C}$ for $30 \mathrm{~s}, 55^{\circ} \mathrm{C}$ for $30 \mathrm{~s}, 72^{\circ} \mathrm{C}$ for $30 \mathrm{~s}$ by $\mathrm{T} 100$ thermal cycler (Thermo Fisher Scientific). PCR reactions for 
endosphere and episphere samples were conducted with 2.5 $\mu \mathrm{l}$ of genomic DNA, $1 \mu \mathrm{l}$ of each primer (10 pmol), $2.5 \mu \mathrm{l}$ of each PNA probe $(7.5 \mu \mathrm{M}), 12.5 \mu 1$ of KAPA HiFi HotStart ReadyMix (Roche, Basel, Swiss) in a final volume $22 \mu \mathrm{l}$, following condition: at initial denaturation step was $95^{\circ} \mathrm{C}$ for $3 \mathrm{~min}$ and 25 reaction cycle condition was $95^{\circ} \mathrm{C}$ for $30 \mathrm{~s}, 78^{\circ} \mathrm{C}$ for $10 \mathrm{~s}, 55^{\circ} \mathrm{C}$ for $30 \mathrm{~s}, 72^{\circ} \mathrm{C}$ for $30 \mathrm{~s}$. Then, the PCR products were purified using AMPure XP (Beckman Coulter, Brea, CA, USA). Next generation Illumian Miseq sequencing was performed by Macrogen Co. (Seoul, Korea). Raw sequence was manufactured to designate operational taxonomic units (OTUs) by DADA2 (Callahan et al., 2016) version 1.8 guidelines (https://benjjneb.github. io/dada2/tutorial_1_8.html) in R version 4.0. libraries
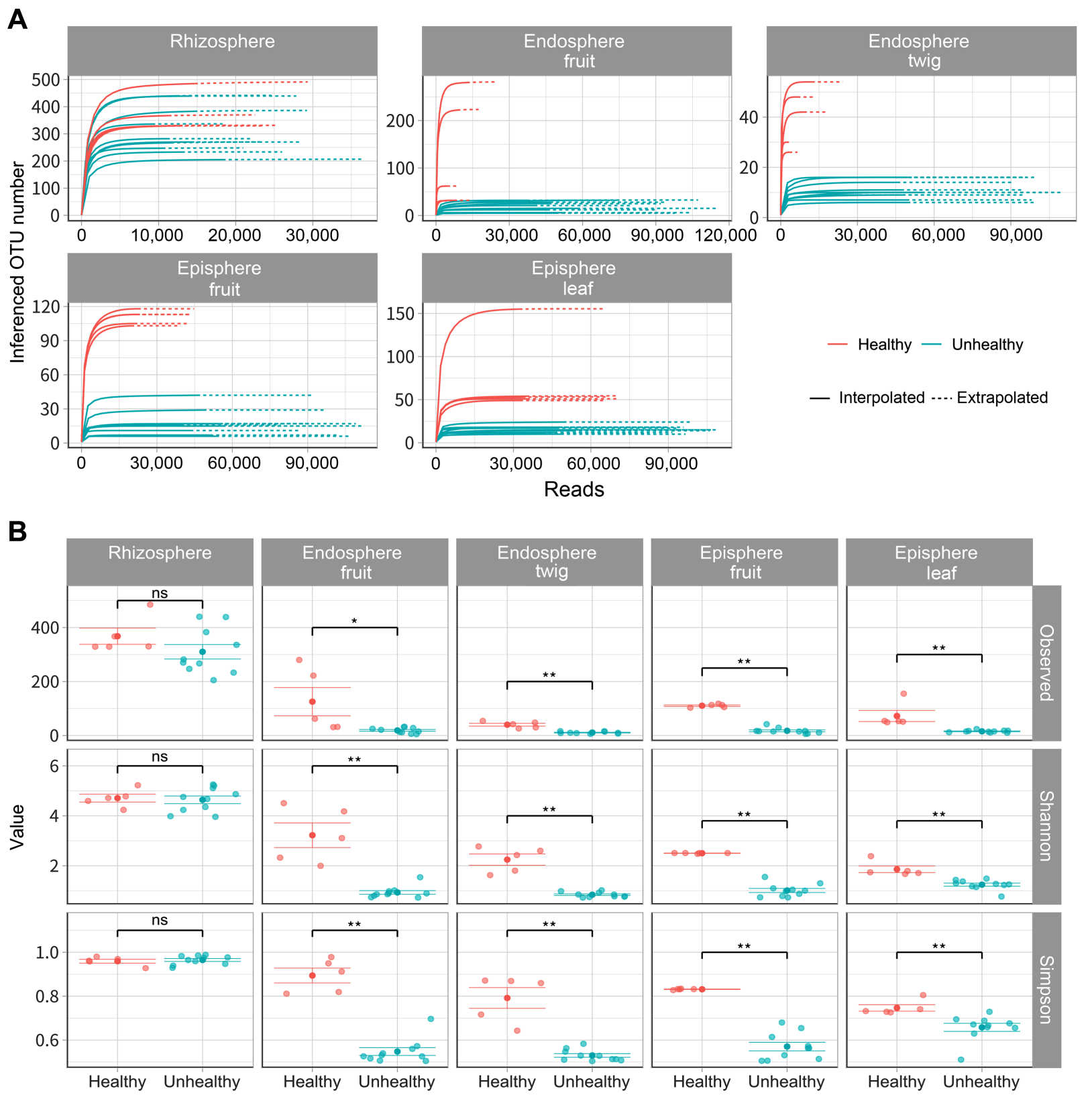

Fig. 1. Species richness and diversity of fire blight infected and healthy apple. Operational taxonomic unit (OTU) was assigned by IDTAXA that has been machine learned to confidence of identification with SILVA 138 SSU. All organization (rhizosphere, endosphere fruit, endosphere twig, episphere fruit, episphere leaf) were conducted in 5 replications. (A) Solid line appeared predicted values within the range of sample. Dotted line expected number of species undetected by the sampling effort. (B) Variables (observed, Shannon, and Simpson) were used to alpha diversity. Star indicate statistically significant differences $(* P \leq 0.05, * * P \leq 0.01)$ between infected and healthy apple trees by Kruskal-Wallis. 
were truncated to 265,215 more than 30 quality score and merged with forward, reverse reads and removed chimera.
Each sequence was identified by IDTAXA (Murali et al., 2018) machine learning algorithm which had been learned

A

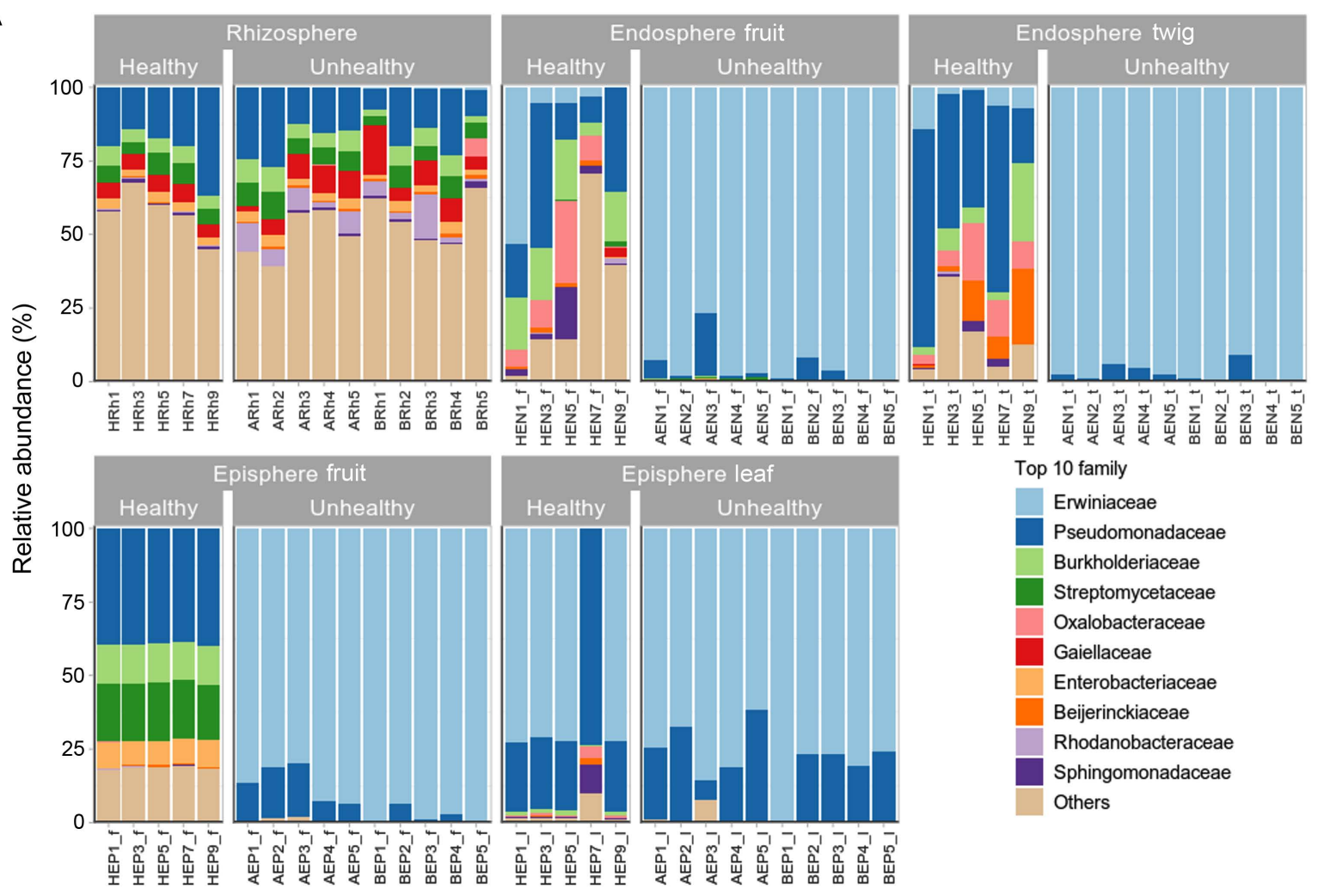

B
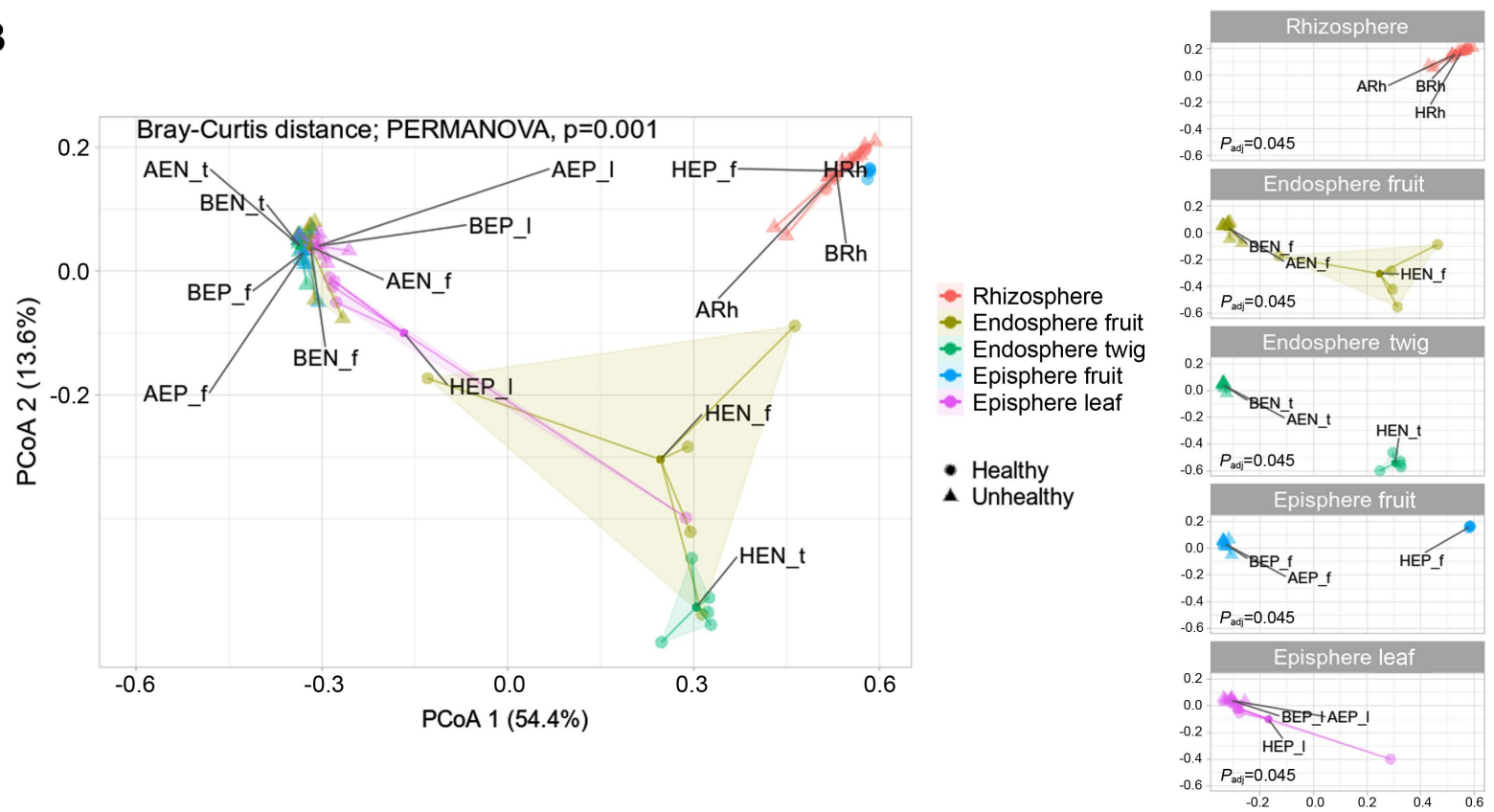

Fig. 2. Diversity and difference of microbial community in healthy and fire blight infected apple. (A) Relative abundance in family level. Family level was cut off in top 10 taxa. (B) Principal coordinates analysis (PCoA) to visualize similarities or dissimilarities based on Bray-Curtis distance. Polygon zone is automatically enclosed points. Statistical analysis conducted by permutational analysis of variance and appeared significant difference between samples $(P=0.001)$. All samples were analyzed in 5 replicates. 
about Silva release 138 (https://www.arb-silva.de) (Quast et al., 2013). Analysis of rarefaction curves, alpha diversity, and beta diversity was conducted by package ggiNEXT (version 2.0.20), pyloseq (version 3.12), vegan (version 2.5-7) and others. Principal coordinates analysis (PCoA) appeared to visualize similarities and dissimilarities based on Bray-Curtis distance. Deseq version 3.12 was used to analyze metabolite pathways in each sample. Graph visualization was performed by ggplot2 version 3.3.3. and Kruskal-Wallis test was used to statistical analysis (Kruskal and Wallis, 1952).

To compare bacterial composition according to infection of E. amylovora, a total of 4,393,392 reads were identified and these sequences were clustered into 1,034,743 for orchard A (unhealthy), 985,836 for orchard B (unhealthy), 404,438 for C orchard (healthy) in 2,425,017 taxonomic units (Supplementary Table 2). In endosphere (fruit, twig) of unhealthy trees inferred OTU numbers showed below 32 and 16 respectively (Fig. 1A). OTU numbers of episphere (fruit, leaf) of unhealthy trees appeared below 40, 23. OTU numbers of endosphere (fruit, twig) and episphere (fruit, leaf) were higher in healthy trees than E. amylovora infected trees according to predicted values. Bacterial alpha diversities had a similar rhizosphere value regardless of fire blight disease occurrence (Fig. 1B). However, all other tissues showed high alpha diversities values in healthy trees than the infected trees. These results were able to confirm a significant difference between E. amylovora infection by Kruskal-Wallis analyses and all data were available at GenBank (Supplementary Table 3).

In the rhizosphere, healthy and infected trees had similar bacterial communities occupied by Pseudomonadaceae, Burkholderiaceae, Streptomycetaceae, and Gaiellaceae (Fig. 2A). Pseudomonadaceae comprised $7-36 \%$ of the
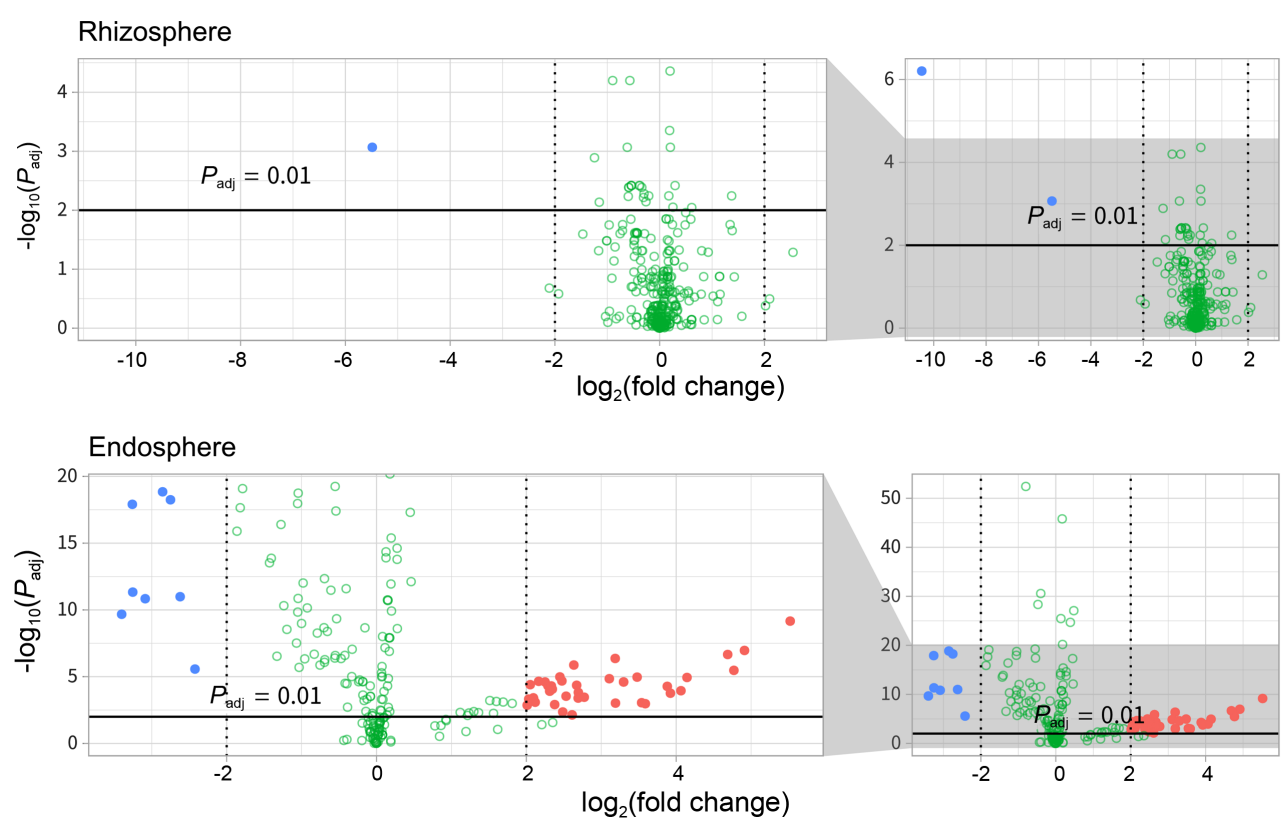

- Unhealthy group

- Healthy group

- Not significant

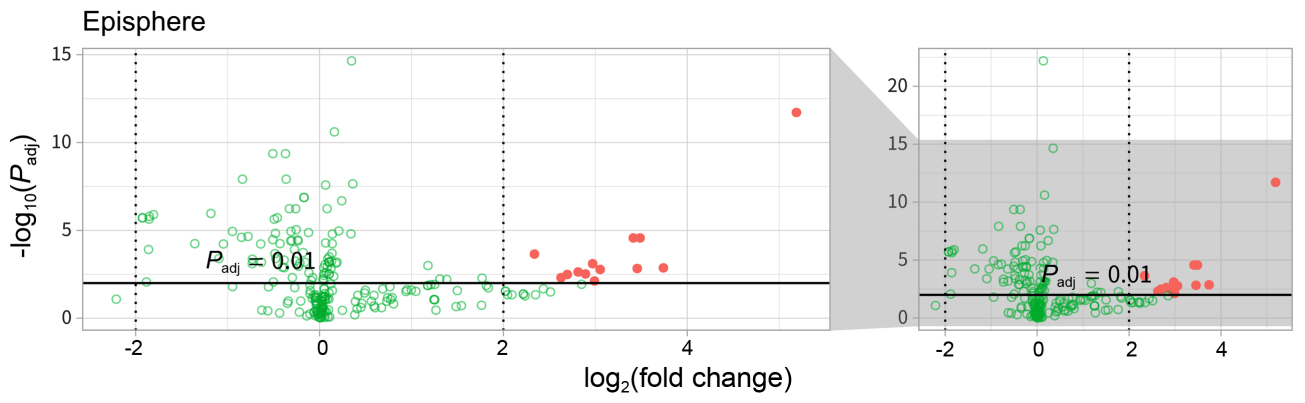

Fig. 3. Metabolite pathway expression in bacterial community confirmation using PICRUSt2 software version 2.3.0. The x-axis is the value substituted by $\log _{2}$. Blue dots indicate pathways that appeared more than $\log _{2}$ fold in the unhealthy group than in the healthy trees. Pink dot means that the pathways of healthy trees are more than $\log _{2}$ fold in unhealthy trees. Not significant dot group appear irrelevant pathway. It was considered that there is a statistical difference when the $P_{\text {adj }}$ value is less than 0.01 . 
rhizosphere. Gaiellaceae comprised to 1-16\%. Burkholderiaceae and Streptomycetaceae dominated the range from $2 \%$ to $7 \%$. In healthy trees endosphere fruit appeared composition of Pseudomonadaceae (8-35\%), Burkolderiaceae (4-20\%), and Oxalobacteraceae (0.7-28\%). In endosphere twigs, Pseudomonadaceae (18-73\%), Burkolderiaceae (2$26 \%$ ), Oxalobacteraceae (3\%-19\%), and Beijerinckiaeceae (0.9-25\%) were detected as abundant members. In episphere fruit, Pseudomonadaceae, Burkholderiaceae, Streptomycetaceae, and Enterobacteriaeceae was observed at $28-29 \%, 13 \%, 18-20 \%$, and 8-9\% abundance, respectively. In the diseased trees, Erwiniaceae constituted $61-99 \%$ in all tissue except the rhizosphere. Excluding Erwiniaceae from the community members, microbial relative abundance appeared from $0.05-32.42 \%$ in all areas except the rhizosphere (Supplementary Table 4). Rhizosphere communities showed no difference in composition whether E. amylovo$r a$ infection was detected or not. A result of statistical significance through permutational analysis of variance analysis confirmed a value of $P_{\text {adj }}$ of 0.001 (Fig. 2B). Bacterial communities of endosphere and episphere in healthy trees from orchard C clearly confirmed the difference between fruit $\&$ twig and fruit $\&$ leaf. Through a result of difference in the bacterial community in healthy and unhealthy trees a significant difference $\left(P_{\text {adj }}=0.045\right)$ was confirmed for endosphere (fruit, twig) and episphere (fruit, leaf) (Fig. 2B).

Compared microbiota in healthy and E. amylovora infected trees had a $61-99 \%$ dominance in organization of unhealthy tree except rhizosphere. The bacterial communities were a difference in endosphere (fruit, twig), episphere (fruit), episphere (leaf). In healthy trees, endosphere showed a high ratio of Oxalobacteraceae and Beijerinckiaeceae, known as nitrogen fixation microbes. Beta diversity resulted in the absence of Erwiniaceae in rhizosphere and dominance of Erwiniaceae in endospheres and epispheres. In previous studies E. amylovora spread by rain, wind, insects, birds, and orchard workers (van der Zwet et al., 2012). It is known that flower is the primary entry route of E. amylovora into the host (Miller and Schroth, 1972). Our finding supports the previous study that E. amylovora infects and multiplies in the episphere of studied specimens. Microbiomes of healthy and unhealthy trees, as well as episphere communities, showed similar structures but there was a significant difference in PCoA $\left(P_{\text {adj }}=0.045\right)$. This seems to be a difference because the diversity and richness of other bacteria are higher than those of infected trees.

Degree of metabolites related to gene expression of the presented bacteria community were predicted (Fig. 3). In

Table 1. The common pathway at endosphere and episphere in healthy trees

\begin{tabular}{llrr}
\hline Category & \multicolumn{1}{c}{ Pathway } & $\log _{2} \mathrm{FC}$ & $P_{\text {adj }}$ \\
\hline Aromatic compound degradation & Toluene degradation III (aerobic) (via p-cresol) & $2,993.32$ & $3.99 \mathrm{E}-06$ \\
& Catechol degradation to 2-hydroxypentadienoate II & $1,472.48$ & 0.000573 \\
& Methylcatechol degradation (ortho cleavage) & $1,905.38$ & 0.000804 \\
& Catechol degradation II (meta-cleavage pathway) & $2,041.65$ & 0.001093 \\
& Superpathway of salicylate degradation & $1,928.15$ & 0.001215 \\
& Catechol degradation I (meta-cleavage pathway) & $2,454.65$ & 0.001908 \\
Sugar acid degradation & D-galacturonate degradation I & $2,896.16$ & $4.87 \mathrm{E}-05$ \\
& Superpathway of $\beta$-D-glucuronosides degradation & 645.45 & 0.003219 \\
Nitrogen compound metabolism & Urea cycle & $2,406.85$ & $3.97 \mathrm{E}-06$ \\
Porphyrin compound biosynthesis & Heme biosynthesis & $2,695.71$ & 0.000447 \\
Proteinogenic amino acid biosynthesis & L-isoleucine biosynthesis IV & $1,350.13$ & 0.000499 \\
\hline
\end{tabular}

Table 2. Pathway of episphere in unhealthy trees

\begin{tabular}{|c|c|c|c|}
\hline Category & Pathway & $\log _{2} \mathrm{FC}$ & $P_{\text {adj }}$ \\
\hline \multirow{3}{*}{ Aromatic compound degradation } & Gallate degradation I & $1,965.04$ & $6.81 \mathrm{E}-21$ \\
\hline & Methylgallate-degradation & $2,235.27$ & $3.18 \mathrm{E}-20$ \\
\hline & Gallate degradation II & $1,933.83$ & 8.04E-20 \\
\hline \multirow{2}{*}{ Lipopolysaccharide biosynthesis } & Superpathway of (Kdo $)_{2}$-lipid A biosynthesis & $4,539.77$ & $1.55 \mathrm{E}-12$ \\
\hline & Enterobacterial common antigen biosynthesis & $4,125.39$ & 4.13E-11 \\
\hline Sugar alcohol degradation & Hexitol fermentation to lactate, formate, ethanol and acetate & $5,188.86$ & $6.86 \mathrm{E}-13$ \\
\hline Sugar nucleotide biosoynthesis & dTDP-N-acetylthomosamine biosynthesis & $5,264.16$ & $2.32 \mathrm{E}-12$ \\
\hline Other biosynthesis & Superpathway of $(R, R)$-butanediol biosynthesis & $4,688.91$ & $9.20 \mathrm{E}-07$ \\
\hline
\end{tabular}


healthy tree endospheres and epispheres, 13 pathways were upregulated and 11 pathways were identified (Table 1); toluene degradation III (aerobic) (via p-cresol), catechol degradation to 2-hydroxypentadienoate II, methylcatechol degradation, catechol degradation II, superpathway of salicylate degradation, catechol degradation I, D-galacturonate degradation $\mathrm{I}$, superpathway of $\beta$-D-glucuronosides degradation, urea cycle, heme biosynthesis, L-isoleucine biosynthesis IV. Comparing pathways in the episphere of healthy and unhealthy trees, 8 metabolites pathways in unhealthy trees were detected as highly different (Table 2). Episphere of E. amylovora infected tree microbiomes showed the following metabolite pathways as upregulated; gallate degradation I, methylgallate-degradation, gallate degradation II, superpathway of (Kdo) ${ }_{2}$-lipid A biosynthesis, enterobacterial common antigen biosynthesis, hexitol fermentation to lactate, dTDP- $N$-acetylthomosamine biosynthesis, and superpathway of $(R, R)$-butanediol biosynthesis. Among the differently regulated pathways, hexitol fermentation to lactate, dTDP-N-acetylthomosamine biosynthesis, superpathway of $(R, R)$-butanediol biosynthesis are related to sucrose metabolites, which was reported to be important for host colonization of E. amylovora (Bogs and Geider et al., 2000; Koczan et al., 2009; Kube et al., 2010). Our research could be used to understand environment and control E. amylovora in the future.

\section{Conflicts of Interest}

Youn-Sig Kwak, a contributing editor of the Plant Pathology Journal, was not involved in the editorial evaluation or decision to publish this article. All remaining authors have declared no conflicts of interest.

\section{Acknowledgments}

This research was supported by the "Cooperative Research Program for Agriculture Science \& Technology Development (PJ014934) from Rural Development Administration of Korea.

\section{Electronic Supplementary Material}

Supplementary materials are available at Journal of Pathology and Translational Medicine (https://jpatholtm.org).

\section{References}

Aćimović, S. G., Zeng, Q., McGhee, G. C., Sundin, G. W. and Wise, J. C. 2015. Control of fire blight (Erwinia amylovora) on apple trees with trunk-injected plant resistance inducers and antibiotics and assessment of induction of pathogenesisrelated protein genes. Front. Plant Sci. 6:16.

Ait Bahadou, S., Ouijja, A., Karfach, A., Tahiri, A. and Lahlali, R. 2018. New potential bacterial antagonists for the biocontrol of fire blight disease (Erwinia amylovora) in Morocco. Microb. Pathog. 117:7-15.

Bengtsson-Palme, J., Kristiansson, E. and Larsson, D. G. J. 2018. Environmental factors influencing the development and spread of antibiotic resistance. FEMS Microbiol. Rev. 42:fux053.

Bogs, J. and Geider, K. 2000. Molecular analysis of sucrose metabolism of Erwinia amylovora and influence on bacterial virulence. J. Bacteriol. 182:5351-5358.

Born, Y., Fieseler, L., Thöny, V., Leimer, N., Duffy, B. and Loessner, M. J. 2017. Engineering of bacteriophages Y2::dpoL1$C$ and Y2::lux $A B$ for efficient control and rapid detection of the fire blight pathogen, Erwinia amylovora. Appl. Environ. Microbiol. 83:e00341-e00317.

Broggini, G. A. L., Duffy, B., Holliger, E., Schärer, H.-J., Gessler, C. and Patocchi, A. 2005. Detection of the fire blight biocontrol agent Bacillus subtilis BD170 (Biopro ${ }^{\circledR}$ ) in a Swiss apple orchard. Eur. J. Plant Pathol. 111:93-100.

Bubán, T. and Orosz-Kovács, Z. 2003. The nectary as the primary site of infection by Erwinia amylovora (Burr.) Winslow et al.: a mini review. Plant Syst. Evol. 238:183-194.

Cabrefiga, J., Bonaterra, A. and Montesinos, E. 2007. Mechanisms of antagonism of Pseudomonas fluorescens EPS62e against Erwinia amylovora, the causal agent of fire blight. Int. Microbiol. 10:123-132.

Callahan, B. J., McMurdie, P. J., Rosen, M. J., Han, A. W., Johnson, A. J. A. and Holmes, S. P. 2016. DADA2: High-resolution sample inference from Illumina amplicon data. Nat. Methods. 13:581-583.

Cui, Z., Huntley, R. B., Zeng, Q. and Steven, B. 2021. Temporal and spatial dynamics in the apple flower microbiome in the presence of the phytopathogen Erwinia amylovora. ISME J. 15:318-329.

Kim, D.-R., Cho, G., Jeon, C.-W., Weller, D. M., Thomashow, L. S., Paulitz, T. C. and Kwak, Y.-S. 2019a. A mutualistic interaction between Streptomyces bacteria, strawberry plants and pollinating bees. Nat. Commun. 10:4802.

Kim, M.-J., Chae, D.-H., Cho, G., Kim, D.-R. and Kwak, Y.-S. 2019b. Characterization of antibacterial strains against kiwifruit bacterial canker pathogen. Plant Pathol. J. 35:473-485.

Koczan, J. M., McGrath, M. J., Zhao, Y. and Sundin, G. W. 2009. Contribution of Erwinia amylovora exopolysaccharides amylovoran and levan to biofilm formation: implications in pathogenicity. Phytopathology 99:1237-1244.

Kruskal, W. H. and Wallis, W. A. 1952. Use of ranks in onecriterion variance analysis. J. Am. Stat. Assoc. 47:583-621.

Kube, M., Migdoll, A. M., Gehring, I., Heitmann, K., Mayer, Y., Kuhl, H., Knaust, F., Geider, K. and Reinhardt, R. 2010. Genome comparison of the epiphytic bacteria Erwinia billingiae 
and E. tasmaniensis with the pear pathogen E. pyrifoliae. BMC Genomics 11:393.

Lundberg, D. S., Yourstone, S., Mieczkowski, P., Jones, C. D. and Dangl, J. L. 2013. Practical innovations for high-throughput amplicon sequencing. Nat. Methods 10:999-1002.

McManus, P. S., Stockwell, V. O., Sundin, G. W. and Jones, A. L. 2002. Antibiotic use in plant agriculture. Annu. Rev. Phytopathol. 40:443-465.

Miller, T. D. and Schroth, M. N. 1972. Monitoring the epiphytic population of Erwinia amylovora on pear with a selective medium. Phytopathology 62:1175-1182.

Murali, A., Bhargava, A. and Wright, E. S. 2018. IDTAXA: a novel approach for accurate taxonomic classification of microbiome sequences. Microbiome 6:140.

Pusey, P. L., Stockwell, V. O., Reardon, C. L., Smits, T. H. M. and Duffy, B. 2011. Antibiosis activity of Pantoea agglomerans biocontrol strain E325 against Erwinia amylovora on apple flower stigmas. Phytopathology 101:1234-1241.

Quast, C., Pruesse, E., Yilmaz, P., Gerken, J., Schweer, T., Yarza, P., Peplies, J. and Glöckner, F. O. 2013. The SILVA ribosomal RNA gene database project: improved data processing and web-based tools. Nucleic Acids Res. 41:D590-D596.

Ritchie, H. and Roser, M. 2020. Agriculture production. Published online at OurWorldindata.org. URL https://ourworldindata.org/agricultural-production [19 July 2021].

Roselló, G., Bonaterra, A., Francés, J., Montesinos, L., Badosa, E. and Montesinos, E. 2013. Biological control of fire blight of apple and pear with antagonistic Lactobacillus plantarum. Eur. J. Plant Pathol. 137:621-633.
Sholberg, P., Bedford, K. E., Haag, P. and Randall, P. 2001. Survey of Erwinia amylovora isolates from British Columbia for resistance to bactericides and virulence on apple. Can. J. Plant Pathol. 23:60-67.

van der Zwet, T., Orolaza-Halbrendt, N. and Zeller, W. 2012. Fire blight: history, biology, and management. American Phytopathological Society, St. Paul, MN, USA. 421 pp.

Vincent, P. J., Brunner, J. F., Grove, G. G., Petit, B., Tangren, G. V. and Jones, W. E. 2010. A web-based decision support system to enhance IPM programs in Washington tree fruit. Pest Manag. Sci. 66:587-595.

Wassermann, B., Müller, H. and Berg, G. 2019. An apple a day: which bacteria do we eat with organic and conventional apples? Front. Microbiol. 10:1629.

Williamson, S. J. and Yooseph, S. 2012. From bacterial to microbial ecosystems (metagenomics). Methods Mol. Biol. 804:3555.

Yao, H., Sun, X., He, C., Maitra, P., Li, X.-C. and Guo, L.-D. 2019. Phyllosphere epiphytic and endophytic fungal community and network structures differ in a tropical mangrove ecosystem. Microbiome 7:57.

Zhao, Y.-Q., Tian, Y.-L., Wang, L.-M., Geng, G.-M., Zhao, W.J., Hu, B.-S. and Zhao, Y.-F. 2019. Fire blight disease, a fastapproaching threat to apple and pear production in China. $J$. Integr. Agric. 18:815-820.

Zheng, P.-F., Yang, Y.-Y., Zhang, S., You, C.-X., Zhang, Z.-L. and Hao, Y.-J. 2020. Identification and functional characterization of MdPIF3 in response to cold and drought stress in Malus domestica. Plant Cell Tissue Organ Cult. 144:435-447. 